the effectiveness of adjuvant therapy for these aggressive tumors. The role of adjuvant radiation therapy is not well defined but is generally advocated because it might decrease the incidence of recurrent tumor. Primary PA sarcoma has a predilection to result in metastatic disease because of its tendency to embolize into the pulmonary arterial tree. Chemotherapy might be effective against microscopic metastatic disease and might decrease the burden of recurrent pulmonary and other systemic disease; however, there has been limited experience with this in the past.

In summary, we present 2 cases of primary PA sarcoma that mimicked pulmonary thromboembolic disease. In both patients the diagnosis of PA sarcoma was made only after pathology was reviewed postoperatively. Despite diagnostic, operative, and oncologic advances over the last few decades, PA sarcoma still remains a diagnostic dilemma associated with a dismal prognosis.

\section{References}

1. Kruger I, Borowski A, Horst M, de Vivie ER, Theissen P, GrossFengels W. Symptoms, diagnosis and therapy of primary sarcoma of the pulmonary artery. Thorac Cardiovasc Surg. 1990;38:91-5.

2. Anderson MB, Kriett JM, Kapelanski DP, Tarazi R, Jamieson SW. Primary pulmonary artery sarcoma: a report of six cases. Ann Thorac Surg. 1995;59:1487-90.

3. Rafal RB, Nichols JN, Markisz JA. Pulmonary artery sarcoma: diagnosis and postoperative follow-up with gadolinium-diethyl-enetriamine pentaacetic acid-enhanced magnetic resonance imaging. Mayo Clin Proc. 1995;70:173-6.

4. Mayer E, Kriegsmann J, Gaumann A, Kauczor HU, Dahm M, Hake U, et al. Surgical treatment of pulmonary artery sarcoma. J Thorac Cardiovasc Surg. 2001;121:77-82.

5. Talbot SM, Taub RN, Keohan ML, Edwards N, Galantowicz ME, Schulman SC. Combined heart and lung transplantation for unresectable primary cardiac sarcoma. J Thorac Cardiovasc Surg. 2002; 124:1145-8.

\title{
Surgical repair of a leaking double postinfarction left ventricular pseudoaneurysm
}

Predrag Milojevic, MD, FETCS, Vojislava Neskovic, MD, DEAA, Milan Vukovic, MD, Dusko Nezic, MD, PhD, FETCS, and Bosko Djukanovic, MD, PhD, Belgrade, Serbia and Montenegro

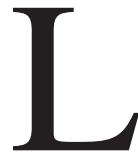

eft ventricular pseudoaneurysm is an uncommon complication of transmural myocardial infarction. It usually forms several weeks after the infarction on the inferior or posterolateral left ventricular wall when cardiac rupture is contained by the adherent pericardium.

Pseudoaneurysm is characterized by a narrow neck in comparison with the diameter of the pseudoaneurysmal sac. Through this sharp discontinuity of myocardial tissue, the pseudoaneurysm communicates with the left ventricular chamber, and bidirectional blood flow can be registered by means of color Doppler echocardiography during the cardiac circle. Considering the risk of secondary rupture or leaking, different treatments are recommended.

We present a case of double inferoposterior left ventricular pseudoaneurysm. To our knowledge, this is the first reported case of double pseudoaneurysm successfully surgically repaired.

\footnotetext{
From the Department of Cardiac Surgery, Dedinje Cardiovascular Institute, Belgrade, Serbia and Montenegro.

Received for publication March 8, 2004; revisions requested March 29, 2004; accepted for publication April 6, 2004.

Address for reprints: Predrag Milojevic, MD, FETCS, Department of Cardiac Surgery II, Dedinje Cardiovascular Institute, M. Tepica 1, 11040 Belgrade, Serbia and Montenegro (E-mail: pmilojevic@ sezampro.yu).

J Thorac Cardiovasc Surg 2004;128:765-7

$0022-5223 / \$ 30.00$

Copyright (C) 2004 by The American Association for Thoracic Surgery

doi:10.1016/j.jtcvs.2004.04.021
}

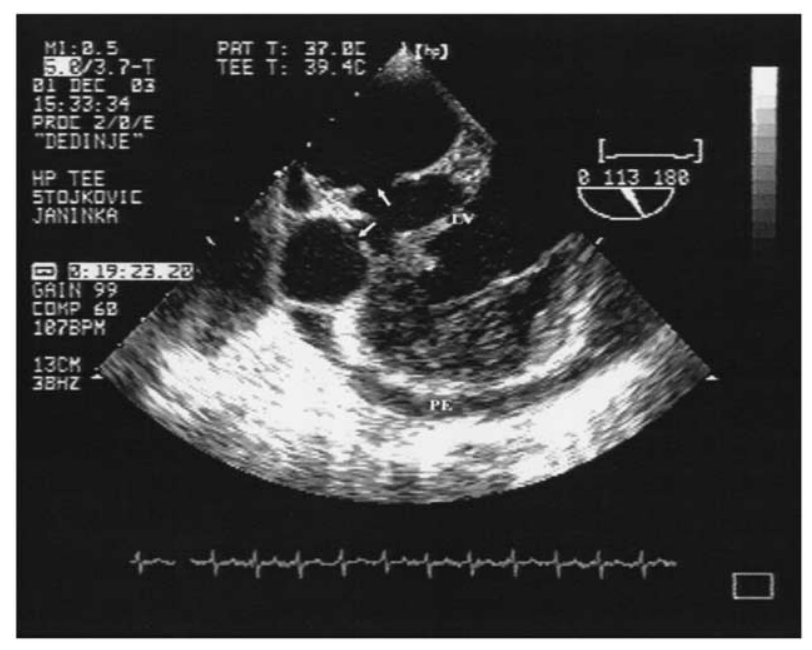

Figure 1. Transesophageal echocardiography: modified longitudinal 2-chamber view. Discontinuity of the inferoposterior myocardial wall at 2 separate places (arrows), with 2 narrow-neck aneurysmal sacs, indicating pseudoaneurysm formation is shown. $L V$, Left ventricle; $P E$, pericardial effusion.

\section{Clinical Summary}

A 45-year-old obese woman was transferred to our institution on an emergency basis with signs of imminent pericardial tamponade. Three months previously, she had acute transmural inferoposterior myocardial infarction that was treated conservatively. At the time 

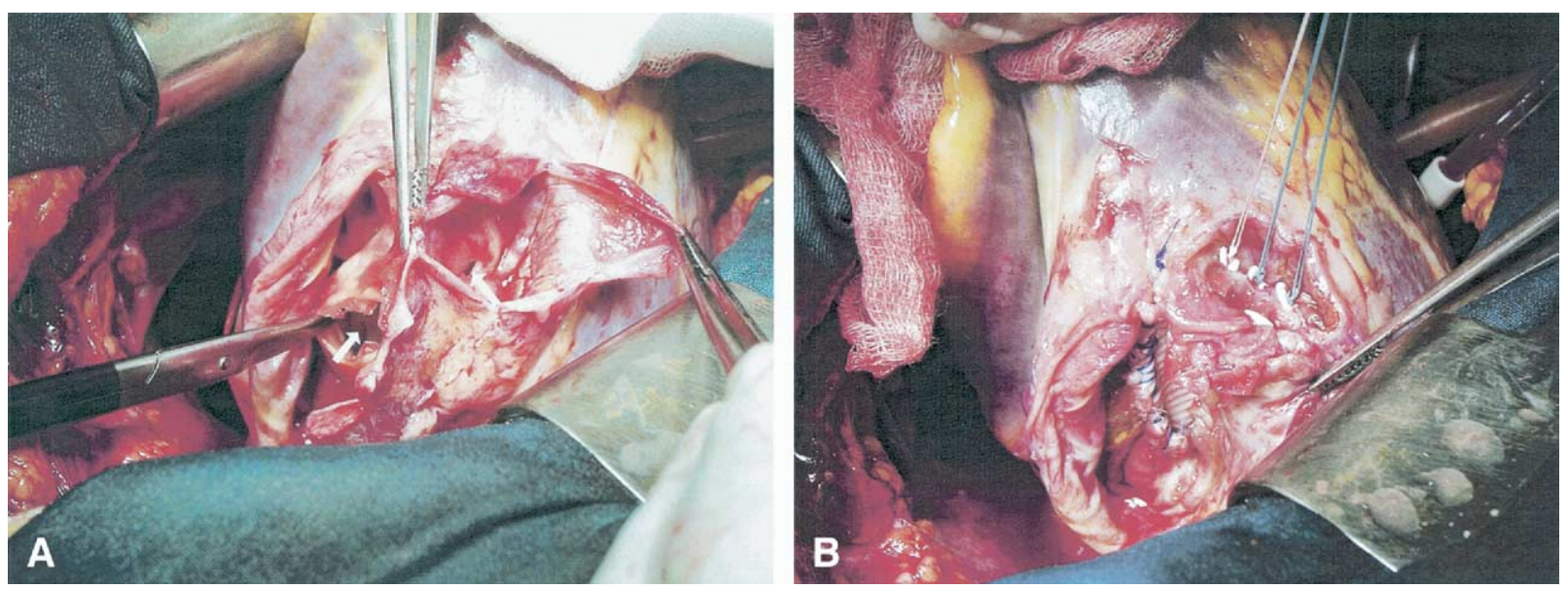

Figure 2. Intraoperative findings: A, double myocardial rupture (arrows) with 2 pseudoaneurysmal sacs; B, repaired myocardial defects.

of the initial event and 1 month after, routine transthoracic echocardiography demonstrated akinesis of the inferoposterior wall, with an estimated ejection fraction of $45 \%$ and no other abnormalities. Because of recurrent chest pain and dyspnea with persisting inferior ST-segment elevation on electrocardiography, the patient underwent treadmill stress testing 2 times, and the results of both tests were negative.

On the day of admission to our institution, chest radiography showed an enlarged heart with a localized bulge on the right contour of the cardiac silhouette. Transthoracic and transesophageal echocardiography demonstrated a $15-\mathrm{mm}$ circular pericardial effusion, compression of the right atrium, and the presence of 2 separate pseudoaneurysms that communicated with the left ventricular cavity. The larger one was located on the inferoposterior left ventricular wall below the posteromedial papillary muscle and was $67 \times 35 \mathrm{~mm}$ in diameter, with a $13-\mathrm{mm}$ myocardial defect. The smaller one was located between the 2 heads of the papillary muscle and was $29 \times 28 \mathrm{~mm}$ in diameter, with a 7-mm defect (Figure 1). Also, trivial mitral valve regurgitation was detected. Subsequent coronary angiography revealed proximal right coronary artery occlusion.

Emergency cardiac surgery was performed. Cardiopulmonary bypass was instituted through femoral cannulation. The pericardial cavity was full of blood without detectable leakage from the pseudoaneurysms at the time. The larger pseudoaneurysm was incised first, and the ventricular defect was closed with a Dacron patch, whereas the smaller pseudoaneurysm was closed with direct sutures (Figure 2). Tissue glue was applied topically, and the pseudoaneurysmal walls were overspread. The mitral valve was not touched. Single-vein bypass was performed on the right coronary artery. The postoperative course was uneventful, and the patient was discharged on the ninth postoperative day.

\section{Discussion}

Left ventricular pseudoaneurysm is a serious complication of transmural myocardial infarction. Generally, it appears several weeks after myocardial infarction, and more then half are localized on the posterolateral wall. Anterior myocardial infarctions are often associated with true aneurysm formation or, rarely, with free wall rupture that results in hemopericardium, tamponade, and death. An inflammatory reaction of the posterior pericardium might result in pericardial adhesions and formation of a posterior left ventricular pseudoaneurysm. ${ }^{1-3}$ The pseudoaneurysmal sac communicates with the left ventricle through the defect on the myocardial wall. The diameter of the defect is less than half the maximum diameter of the pseudoaneurysm. The wall of the pseudoaneurysm contains pericardium and clot without normal myocardial tissue. ${ }^{3}$

Pseudoaneurysms are often asymptomatic, and diagnosis is accidental. ${ }^{1-3}$ Considering the risk of leaking or secondary rupture, surgical $^{3,4}$ treatment is recommended, although the long-term outcome of untreated pseudoaneurysm has been reported. ${ }^{5}$ Echocardiography usually allows establishment of a definite diagnosis. ${ }^{2}$

In our patient, an extremely rare double postinfarction pseudoaneurysm was founded. To our knowledge, this is the first reported case of double pseudoaneurysm successfully surgically repaired.

Double posterior wall rupture and pseudoaneurysm formation probably occurred 2 or 3 months after infarction, and leaking from them caused worsening of the patient's clinical condition. Echocardiography was the key in establishing correct diagnosis and planning subsequent emergency surgical treatment. Preoperatively, only coronary angiography was performed. Contrast left ventriculography was not performed because echocardiography clearly demonstrated 2 separate sacs in communication with the left ventricle through 2 separate wall defects and no communication between them (Figure 1). A curiosity of this case was the 2 negative treadmill stress test results obtained in the postinfarction period. Correct diagnosis was made on time by using noninvasive diagnostic modalities, and emergency operation resulted in successful postoperative recovery.

\section{References}

1. Frances C, Romero A, Grady D. Left ventricular pseudoaneurysm. J Am Coll Cardiol. 1998;32:557-61. 
2. Brown SL, Gropler RJ, Harris KM. Distinguishing left ventricular aneurysm from pseudoaneurysm. Chest. 1997;111:1403-9.

3. Yeo TC, Malouf JF, Oh JK, Seward JB. Clinical profile and outcome in 52 patients with cardiac pseudoaneurysm. Ann Intern Med. 1998;128: 299-305.
4. Pretre R, Linka A, Jenni R, Turina MI. Surgical treatment of acquired left ventricular pseudoaneurysms. Ann Thorac Surg. 2000;70:553-7.

5. Moreno R, Gordillo E, Zamorano J, Almeria C, Garcia-Rubira JC, Fernandez-Ortiz A, et al. Long term outcome of patients with postinfarction left ventricular pseudoaneurysm. Heart. 2003;89:1144-6.

\title{
Atrial septal mass: Transesophageal echocardiographic assessment
}

\author{
Giulio Rizzoli, MD, ${ }^{a}$ Tomaso Bottio, MD, PhD, ${ }^{a}$ Demetrio Pittarello, MD, ${ }^{a}$ Massimo Napodano, MD, ${ }^{c}$ Gaetano Thiene, MD, \\ and Cristina Basso, MD, $\mathrm{PhD},{ }^{\mathrm{b}}$ Padua, Italy
}

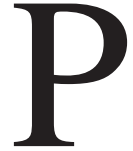

rimary tumors are very rare, with the incidence in necroscopy series being between $0.0017 \%$ and $0.28 \%{ }^{1}$ Angiomas account for less than $5 \%$ of all these. Today, few reports discussing the clinical manifestation and pathologic appearance of cardiac angiomas have been published worldwide in the literature, and very few articles report surgical angioma excision. ${ }^{2}$

The angioma is a histologically benign tumor without infiltrative propensity, and it is mostly described in the subendocardial layers of the right atrium in adult female patients.

Although these are incidental findings in the majority of cases because they are asymptomatic, such tumors might be associated with a wide range of atypical and different symptoms that are related to the cardiac chambers involved or to the specific cardiac site of origin.

At gross examination, this tumor appears like a circumscribed mass in the subendocardial layer. Echocardiographic imaging techniques, either transthoracic or transesophageal, allow a differential diagnosis, whereas cardiac catheterization appears to be unnecessary. We report the case of a symptomatic patient undergoing successful surgical intervention for an interatrial septal angioma detected by means of 2-dimensional echocardiography.

\section{Clinical Summary}

A 62-year-old woman with effort-induced dyspnea was referred to us with transesophageal echocardiography-based diagnosis of an atrial septal mass. Physical examination was unremarkable without the appearance of a cardiac murmur. A 12-lead electrocardiogram showed normal sinus rhythm, without evidence of pathologic waves. The transesophageal echocardiogram showed a lobulated,

\footnotetext{
From the Institute of Cardiovascular Surgery, ${ }^{\mathrm{a}}$ Cardiology, ${ }^{\mathrm{b}}$ and Pathology, University of Padua Medical School, Padua, Italy.

Received for publication March 3, 2004; accepted for publication March 22, 2004.

Address for reprints: Cristina Basso, $\mathrm{MD}, \mathrm{PhD}$, Istituto di Anatomia Patologica, Via A. Gabelli, 61, 35121 Padova, Italy (E-mail: cristina.basso@ unipd.it).

J Thorac Cardiovasc Surg 2004;128:767-9

$0022-5223 / \$ 30.00$

Copyright (C) 2004 by The American Association for Thoracic Surgery

doi:10.1016/j.jtcvs.2004.03.053
}

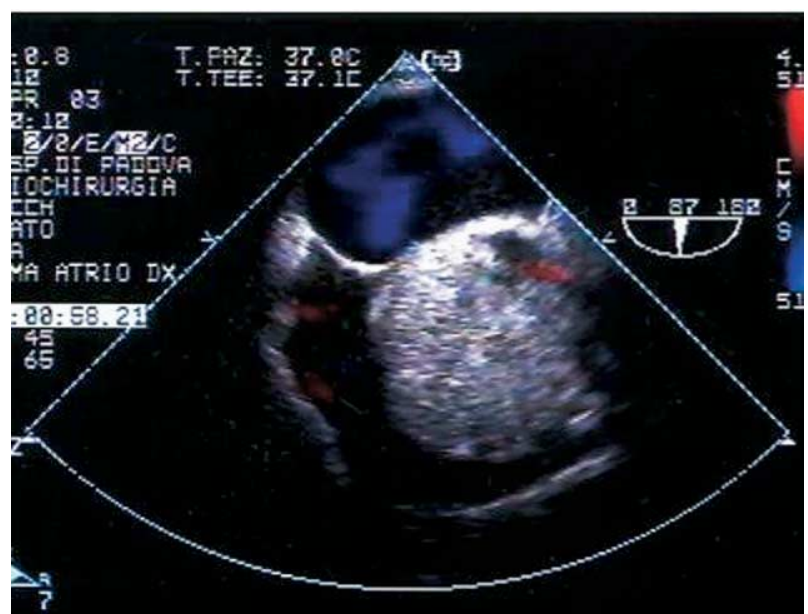

Figure 1. Transesophageal echocardiography shows an interatrial septal cystic mass that interferes with right blood flow by protruding into the right atrium and that is limited in its extension by the endocardial layers. At Doppler examination, an afferent coronary branch is discovered. The left atrium is at the top of the screen.

fixed mass $(6.4 \mathrm{~cm}$ in diameter), which was related to the atrial septum (Figure 1) and was severely restricting the superior vena caval inflow. The tumor expanded in the right atrium, which was also enlarged. Within the tumor mass, a cyst had been discovered with an afferent arterial vessel by means of color Doppler analysis. The right ventricle and left cardiac chambers were within normal values for dimension and function. Tricuspid leaflet motion was not altered, and the valve was continent. Cardiac catheterization was performed showing the tumor surrounded by a laminar stream of caval blood and normal coronary arteries. A faint afferent artery originating from the right coronary artery and a faint contrast uptake within the atrial septum could be recognized (Figure 2).

The patient underwent surgical intervention with cardiopulmonary bypass during moderate hypothermia and retrograde cardioplegic arrest. Through a transatrial approach, the bulky atrial septum was carefully incised, and a large spherical mass of $3 \mathrm{~cm}$ in diameter was enucleated from the septal wall. The large cavity at the base of the atrial septum was then obliterated by suturing. Tricuspid valve and mitral valve leaflets appeared normal and 